\title{
INFLUENCE OF THE SURFACE MODIFICATION OF MESOPOROUS ACTIVATED CARBON ON THE REMOVAL OF HUMIC ACID FROM AQUEOUS SOLUTION
}

\author{
Anna Kotodziej ${ }^{a, 6}$ \\ Grażyna Gryglewicz ${ }^{a}$ \\ Philippe Burg ${ }^{b}$ \\ ${ }^{a}$ Wroctaw University of Technology, Faculty of Chemistry, Poland \\ ${ }^{b}$ Paul-Verlaine University-Metz, France
}

\begin{abstract}
Humic acids (HA) constitute the major fraction of natural organic matter in water supplies. HA are very problematic with regard to drinking water treatment and supply since, not being completely removed by conventional treatment processes, they react with chlorine resulting in formation of carcinogenic and regulated disinfection-by products.

Adsorption of brown (BHA) and gray (GHA) fractions of humic acid on starting and modified mesoporous activated carbons was investigated. BHA and GHA are fractions of humic acid extracted from young brown coal (Czech Republic) which differ essentially in their characteristics in terms of structure and physicochemical properties. Mesoporous activated carbon was modified by two ways: ammonization $(\mathrm{AC} / \mathrm{N})$ and high-temperature hydrogen treatment $(\mathrm{AC} / \mathrm{H})$. All activated carbons studied, showed higher adsorption capacity towards BHA comparing to GHA, what is attributed to the smaller molecular weight of BHA molecules, as determined by ultrafiltration method. Comparing to starting AC, nearly 2- and 2.5-fold higher removal degree of both $\mathrm{BHA}$ and $\mathrm{GHA}$ was observed for $\mathrm{AC} / \mathrm{N}$ and $\mathrm{AC} / \mathrm{H}$, respectively. This observation was found to be a consequence of the increase in aromacity degree of both adsorbents, as shown by increase in the $\mathrm{C} / \mathrm{H}$ atomic ratio. In the case of $\mathrm{AC} / \mathrm{H}$ the electrostatic interaction between positively charged surface of $\mathrm{AC} / \mathrm{H}$ and $\mathrm{HA}$ molecules, enhances the extent of adsorption. Adsorption results were discussed in terms of Freundlich adsorption model. The shape of isotherm indicates a strong competition for adsorption centers on $\mathrm{AC}$ surface between water and $\mathrm{HA}$ molecules, which decreased in the direction $\mathrm{AC}>\mathrm{AC} / \mathrm{N}>\mathrm{AC} / \mathrm{H}$. At increased ionic strength of the solution $(0.01 \mathrm{M} \mathrm{NaCl})$, no difference in the extent of adsorption between $\mathrm{AC} / \mathrm{N}$ and $\mathrm{AC} / \mathrm{H}$ was observed.
\end{abstract}

\section{KEY WORDS}

Humic acid; Modified activated carbons; Adsorption.

\footnotetext{
${ }^{6}$ Corresponding author. Address: Wrocław University of Technology, Department of Polymer and Carbonaceous Materials, Gdańska 7/9, 50-344 Wrocław, Poland. Tel: +48713206266, Fax: +48-713221580.

E-mail address: anna.kolodziej@pwr.wroc.pl (A. Kołodziej)
} 


\section{INTRODUCTION}

Humic acids (HA) constitute the major fraction of natural organic matter in water supplies decreasing considerably water quality. Since some fractions of HA are not being removed by conventional water purification methods, they remain in treated water and reach the disinfection stage of water treatment leading to the formation of carcinogenic and regulated disinfection-by products via reaction with chlorine [1]. One of the recommended methods for HA removal is adsorption on activated carbon (AC) [2]-[4]. However, adsorption from aqueous solutions is very complex matter affected by many factors including the porous texture and surface chemistry of adsorbent, the size and chemical character of adsorbate, and finally, the solution parameters like ionic strength and $\mathrm{pH}$. Despite many investigations performed in the field of the removal of HA on ACs, sorption capacities and adsorption kinetics reported in the literature are relatively scarce. As a promising method of upgrading the adsorption capacity, the modification of chemical character of the surface has been considered [5].

The objective of this work was to determine the effect of HA nature and the surface chemistry of $\mathrm{AC}$ on adsorptive interactions between $\mathrm{HA}$ and $\mathrm{AC}$ in aqueous solution. For design the sorption system three main assumptions have been made: i) all adsorbents have comparable mesoporous texture to exclude the differences in the adsorption extent caused by diversified porosity of adsorbent; ii) ionic strength is close to zero that implies no screening interaction resulting from the presence of electrolyte in adsorption system and finally iii) $\mathrm{pH}$ of the solution, as typical for water treatment plants on the stage of $\mathrm{AC}$ bed, is slightly higher than neutral. Such configuration of sorption system parameters allows to point out which interactions between $\mathrm{AC}$ and $\mathrm{HA}$ are of the key-meaning for the adsorption processes and further, to indicate if and how the contribution of those interactions changes with $\mathrm{HA}$ and $\mathrm{AC}$ characteristics. We consider such knowledge to be very useful for design and selection of ACs for effective removal of HA regardless of their chemical-physical characteristics and thus, reduction of the risk of disinfection by-products formation.

\section{MATERIALS AND METHODS}

\subsection{Humic substances}

Two molecular fractions of HA, brown humic acid (BHA) and gray humic acid (GHA), which were used for this study, were prepared and characterized by previous researchers [6]. For the adsorption tests, a stock solution of $50 \mathrm{mg} / \mathrm{L}$ concentration was prepared by dissolving $50 \mathrm{mg}$ of HA in $\sim 30 \mathrm{ml}$ of distilled water containing $1.2 \mathrm{ml}$ of $0.1 \mathrm{M} \mathrm{NaOH}$. After dissolution, the solution was filtered on vacuum filtration set through the nitrate-cellulose filters $0.45 \mu \mathrm{m}$. Finally, the filtrate was diluted with distilled water to required concentration.

\subsection{Adsorbents}

The mesoporous AC produced via catalytic gasification of high volatile bituminous coal from Szczygłowice mine [8] was applied as a starting material. The AC was subjected to different treatment in order to modify its surface in terms of chemical composition. Heat treatment under hydrogen was carried out in Carbolite CTF Tube Furnace with a heating rate of $5{ }^{\circ} \mathrm{C} / \mathrm{min}$ and a hydrogen flow of $5 \mathrm{~L} / \mathrm{h}$. After reaching the final temperature $900{ }^{\circ} \mathrm{C}$, the sample was heated at this temperature for $2 \mathrm{~h}$. Ammonization was conducted in a stationary vertical furnace in a fluidized bed. The sample of AC was heated in the nitrogen flow with a heating rate of 
$10{ }^{\circ} \mathrm{C} / \mathrm{min}$ up to $700{ }^{\circ} \mathrm{C}$. Afterwards ammonia was introduced to the reaction system and the sample was heated in the ammonia flow of $9 \mathrm{~L} / \mathrm{h}$ for $2 \mathrm{~h}$.

Before adsorption tests, AC samples were boiled in distilled water for $1 \mathrm{~h}$, and then dried at $60{ }^{\circ} \mathrm{C}$ under vacuum for $24 \mathrm{~h}$. The samples for adsorption tests were stored till use in a vacuum desiccators.

\subsection{Analyses}

For elemental composition analysis (CHNS) of HA a Vario EL analyzer was applied. Oxygen content was determined directly using a Carlo Erba analyzer. The structural parameters of the ACs were determined from adsorption and desorption of $\mathrm{N}_{2}$ at $77 \mathrm{~K}$ by a gas sorption analyzer (Quantachrome Nova 2000). The surface area was calculated from BET equation. From Gurvitch law, on the basis of the amount of gas adsorbed at relative gas pressure $\mathrm{p} / \mathrm{p}_{0}=0.96$, total pore volume was calculated. Mesopore volume was determined from Kelvin equation. From the difference between total pore volume $\left(\mathrm{V}_{\text {tot }}\right)$ and mesopore volume $\left(\mathrm{V}_{\text {mes }}\right)$ the micropore volume $\left(\mathrm{V}_{\text {mic }}\right)$ was determined. The mesopore fraction is expressed as percentage of mesopore volume to the total pore volume $\left(\mathrm{V}_{\text {mes }} / \mathrm{V}_{\text {tot }}\right)$. The $\mathrm{pH}$ PZC $(\mathrm{PZC}$ point of zero charge) of ACs was determined according to the procedure described by Moreno-Castilla et al. [9].

\subsection{Adsorption experiments}

The adsorption of HA from aqueous solution was carried out in a static system at room temperature. For the adsorption isotherm determination, $0.003-0.1 \mathrm{~g}$ of activated carbon was placed into 9 flasks and $0.05 \mathrm{~L}$ of the adsorbate solution $(50 \mathrm{mg} / \mathrm{L})$ was added to each flask. A set of flasks included two additional flasks containing blank solution to check the adsorption of sorbate on the walls. The stoppered flasks were shaken for 5 days to reach steady-state conditions. Before and after contact, the $\mathrm{pH}$ of solution was measured by a digital $\mathrm{pH}$ meter (Mettler Toledo) using a glass electrode.

To establish the equilibrium time and determine the effect of ionic strength, $0.05 \mathrm{~g}$ of activated carbon was placed into a set of Erlenmayers flasks containing $0.05 \mathrm{~L}$ of adsorbate solution of various ionic strength $(\mathrm{I}=0,0.001,0.01 \mathrm{M} \mathrm{NaCl})$. Samples were collected in time intervals and the concentration of solute remaining in the water phase was quantified using a Hitachi U-2800A spectrophotometer at wavelength $254 \mathrm{~nm}$.

\section{RESULTS AND DISCUSSION}

\subsection{Characteristics of humic acid}

The structural features of BHA and GHA were described in details elsewhere [6]. According to the results reported [6] the main difference in the chemical nature of HA fractions lies in their acidity and the $\mathrm{H} / \mathrm{C}$ and $\mathrm{O} / \mathrm{C}$ ratios. A lower $\mathrm{H} / \mathrm{C}$ ratio of $\mathrm{BHA}$ compared to GHA $(0.058$ vs 0.073 ) indicates more aromatic character of the former fraction. Nearly twice higher $\mathrm{O} / \mathrm{C}$ ratio observed for BHA (1.25 vs 0.73 ) proves its more hydrophilic character compared with GHA. Total acidity, determined by solid-state ${ }^{13} \mathrm{C}$ NMR, was 3.54 and $2.25 \mathrm{mmol} / \mathrm{g}$ for BHA and GHA, respectively [6]. This corresponds to the contribution of carboxylic groups amounting to 2.22 (BHA) and 1.42 (GHA) mmol/g. As can be seen in Figure 1, BHA is characterized mainly by molecules of low molecular weights with dominant species of $5-50$ 
$\mathrm{kDa}$. No molecules of sizes greater than $100 \mathrm{kDa}$ are observed for BHA fraction whereas in the case of GHA these molecular patterns constitute nearly $40 \%$ of total fraction [7].

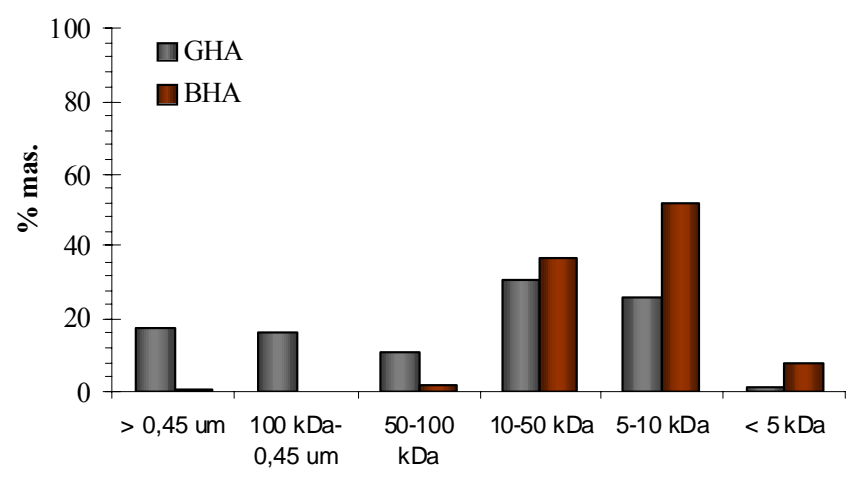

Figure 1. Molecular weight distribution of BHA and GHA determined by ultrafiltration method.

\subsection{Characteristics of adsorbents}

The characteristics of studied ACs, including the elemental composition, porous structure parameters and $\mathrm{pH}_{\mathrm{PZC}}$, are summarized in Table 1. The effect of surface modification is reflected by the increase of $\mathrm{pH}_{\mathrm{PZC}}$ value of $\mathrm{AC} / \mathrm{N}\left(\mathrm{pH}_{\mathrm{PZC}} 7.5\right)$ and $\mathrm{AC} / \mathrm{H}\left(\mathrm{pH}_{\mathrm{PZC}} 8.5\right)$ compared to $\mathrm{AC}$ ( $\mathrm{pH}$ PZC 6.7). Ammonization results in the nitrogen content increase from 0.3 to $0.9 \mathrm{wt} \%$ accompanied by a decrease in the oxygen content from 2.7 to $1.0 \mathrm{wt} \%$. The latter finding can be explained by elimination of less stable oxygen groups and contribution of surface oxygen groups in the reaction with ammonia [10]. When AC is subjected to hydrogen treatment at high temperature, the oxygen content lowers from 2.7 to $0.9 \mathrm{wt} \%$ due to decomposition of oxygen functionalities. This causes an increase in the electron density of the graphene layers improving basicity of carbon. Lowering the $\mathrm{H} / \mathrm{C}$ atomic ratio indicates an increase in the aromacity degree of ACs as follows: $\mathrm{AC} / \mathrm{H}<\mathrm{AC} / \mathrm{N}<\mathrm{AC}$. 


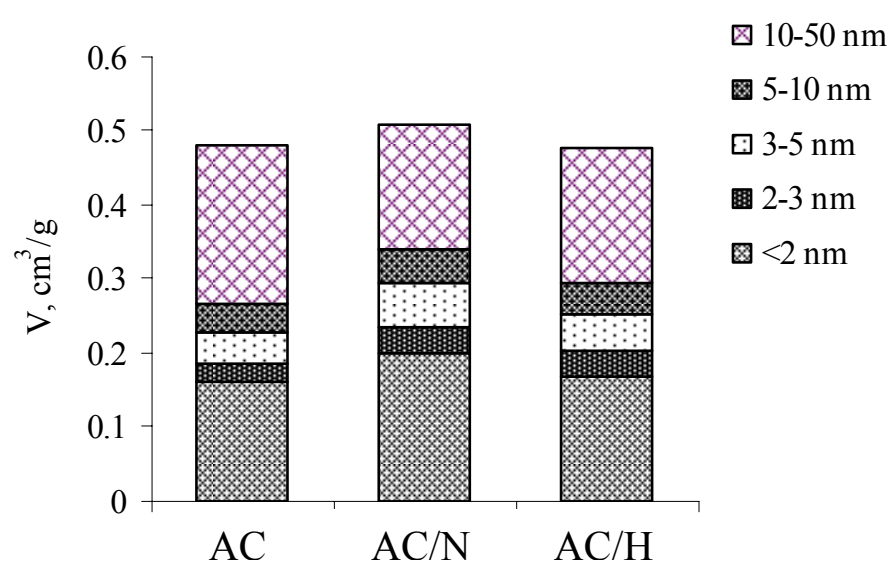

Figure 2. Pore volume distribution of ACs applied in HA adsorption tests.

Table 1. Physicochemical characteristics of activated carbons applied in adsorption tests

\begin{tabular}{llllllllllll}
\hline & \multicolumn{3}{l}{ Elemental analysis } & & & $\begin{array}{l}\mathrm{S}_{\mathrm{BET}}, \\
\mathrm{m}^{2} / \mathrm{g}\end{array}$ & $\begin{array}{l}\mathrm{V}_{\text {tot, }} \\
\mathrm{cm}^{3} / \mathrm{g}\end{array}$ & $\begin{array}{l}\mathrm{V}_{\text {mic, }} \\
\mathrm{cm}^{3} / \mathrm{g}\end{array}$ & $\begin{array}{l}\mathrm{V}_{\text {mes }} \\
\mathrm{cm} 3 / \mathrm{g}\end{array}$ & $\mathrm{V}_{\text {mes }} / \mathrm{V}_{\text {tot }}$, & $p H_{P Z C}$ \\
\hline $\mathrm{AC}$ & 96.4 & 0.6 & 0.3 & 2.7 & $7.47 \cdot 10^{-2}$ & 415 & 0.506 & 0.160 & 0.346 & 0.68 & 6.7 \\
$\mathrm{AC} / \mathrm{N}$ & 97.6 & 0.5 & 0.9 & 1.0 & $6.15 \cdot 10^{-2}$ & 518 & 0.531 & 0.199 & 0.331 & 0.62 & 7.5 \\
$\mathrm{AC} / \mathrm{H}$ & 98.3 & 0.5 & 0.3 & 0.9 & $6.10 \cdot 10^{-2}$ & 452 & 0.510 & 0.170 & 0.336 & 0.65 & 8.5 \\
\hline
\end{tabular}

The ACs are characterized by well developed mesoporosity (see Table 1). The mesopore volume is in the range of $0.331-0.346 \mathrm{~cm}^{3} / \mathrm{g}$ (see Figure 2). It is worth noting that the volume of narrow mesopores $(2-10 \mathrm{~nm})$, in which the HA molecules are preferentially adsorbed, differs insignificantly. Therefore, the difference observed in the HA uptake for tested adsorbents could be explained almost entirely by carbon surface chemistry.

\subsection{Comparison of BHA and GHA adsorption on modified ACs}

The adsorption tests were carried out at neutral $\mathrm{pH}$ value which is typical for water treatment plant in the stage of $\mathrm{AC}$ bed. The initial HAs solution $\mathrm{pH}$ was in the range of 7.5-8. During adsorption process it remained around 7.2-7.5 without any buffer addition. It is well known that due to amphoteric character, the surface of AC can be positively or negatively charged depending on the solution $\mathrm{pH}$. Taking into account $\mathrm{pH}_{\mathrm{PZC}}$ values determined, the surface of $\mathrm{AC}$ is slightly negatively charged $\left(\mathrm{pH}_{\mathrm{PZC}} 6.7\right), \mathrm{AC} / \mathrm{N}$ is around zero charge $\left(\mathrm{pH}_{\mathrm{PZC}} 7.5\right)$, and $\mathrm{AC} / \mathrm{H}$ is charged positively $\left(\mathrm{pH}_{\mathrm{PZC}} 8.5\right)$ under the adsorption conditions tested in our work. Hence, significant differences between ACs in terms of adsorption of HA are expected.

The results of preliminary adsorption test for BHA and GHA on modified ACs versus time are shown in Figure 3. All ACs studied show a higher removal degree for BHA comparing to GHA. It is presumably because of the differences in molecular weight between both HA 
fractions. BHA which exhibits lower molecular weight and molecule size compared to GHA (see Figure 1) can reach more adsorption sites on the carbon surface [3],[11].

It can be clearly seen that the applied modification of the carbon surface leads to an enhanced adsorption of HA from aqueous solution. The uptake of BHA as well as GHA changes in the following direction: $\mathrm{AC}<\mathrm{AC} / \mathrm{N}<\mathrm{AC} / \mathrm{H}$. In the case of non-modified mesoporous $\mathrm{AC}$ the removal of BHA and GHA amounts to $\sim 26$ and $\sim 20 \%$, respectively. Nearly twice higher removal degree of BHA $(\sim 46 \%)$ and GHA $(\sim 42 \%)$ can be observed for AC/N compared to

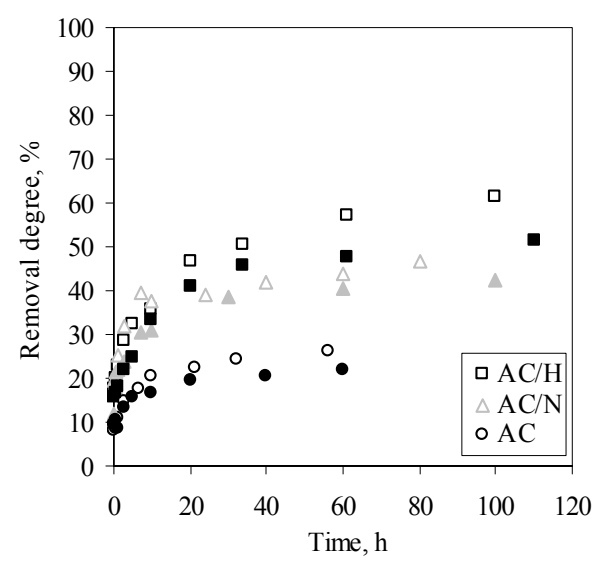

Figure 3. Adsorption of BHA (open symbols) and GHA (closed symbols) versus time on $A C$, $A C / N$ and $A C / H$.

AC. This finding can be explained by electrostatic interactions and carbon aromacity. The electrostatic repulsive forces occurring between the negatively charged HA and non-modified AC surface ( $\left.\mathrm{pH}_{\mathrm{PZC}}<\mathrm{pH}_{\text {solution}}\right)$ can lead to the lower extent of adsorption of both BHA and GHA. The correlation between the HA uptake and the $\mathrm{H} / \mathrm{C}$ ratio of adsorbent suggests that dispersive interaction contribute in the removal of HA from water as well [12]. The higher adsorption extent of $\mathrm{AC} / \mathrm{N}$ compared to $\mathrm{AC}$ can be due to significantly higher degree of aromacity expressed by lower $\mathrm{H} / \mathrm{C}$ ratio of adsorbent (see Table 1). This implies greater electron density on the basal planes of the adsorbent resulting in stronger dispersive forces. The highest removal degree of BHA $(\sim 61 \%)$ and GHA $(\sim 51 \%)$ observed for $\mathrm{AC} / \mathrm{H}$ can be explained by electrostatic attractive interaction between the positively charged carbon surface $\left(\mathrm{pH}_{\mathrm{PZC}}>\right.$ solution $\left.\mathrm{pH}\right)$ and negatively charged HAs which, next to dispersive forces can be consider as the main adsorption mechanism responsible for the enhanced adsorption on $\mathrm{AC} / \mathrm{H}$.

It is interesting to note the larger difference in the uptake of BHA and GHA in case of $\mathrm{AC} / \mathrm{H}$ compared to $\mathrm{AC}$ and $\mathrm{AC} / \mathrm{N}$. As mentioned above the attractive forces are mainly responsible for the enhanced adsorption of $\mathrm{HA}$ fractions by $\mathrm{AC} / \mathrm{H}$. Therefore, this difference is presumably arisen from different charge of BHA and GHA molecules. Indeed, the concentration of carboxylic groups, which are dissociated in the conditions of adsorption test, is twice higher in the BHA fraction than that of GHA (2.22 vs $1.42 \mathrm{mmol} / \mathrm{g} \mathrm{HA}$. of COO) [6]. Hence, BHA will interact stronger with the positively charged surface of $\mathrm{AC} / \mathrm{H}$ leading to a higher adsorption extent compared to GHA. Much higher BHA uptake comparing to GHA is a confirmation for the adsorption mechanism based on electrostatic interactions.

\subsection{Application of Freundlich model}


The adsorption data obtained were interpreted in terms of Freundlich model, expressed by the following equation:

$$
\mathrm{q}_{\mathrm{e}}=\mathrm{K}_{\mathrm{f}} \mathrm{C}_{\mathrm{e}}{ }^{1 / \mathrm{n}}
$$

where $\mathrm{K}_{\mathrm{f}}$ and $1 / \mathrm{n}$ are Freundlich constancies related to the relative adsorption capacity and heterogeneity of the surface adsorption sites, respectively. In general, as the $\mathrm{K}_{\mathrm{f}}$ value increases, the adsorption capacity of adsorbent for a given adsorbate increases. The magnitude of the exponent $1 / \mathrm{n}$, gives an indication of the favorability of adsorption. For irreversibly adsorbed compounds, the $1 / \mathrm{n}$ value is between 0 and 1 . Values of $1 / \mathrm{n}$ greater than 1 indicate unfavorable adsorption and approach infinity for compounds that are not adsorbed [13].
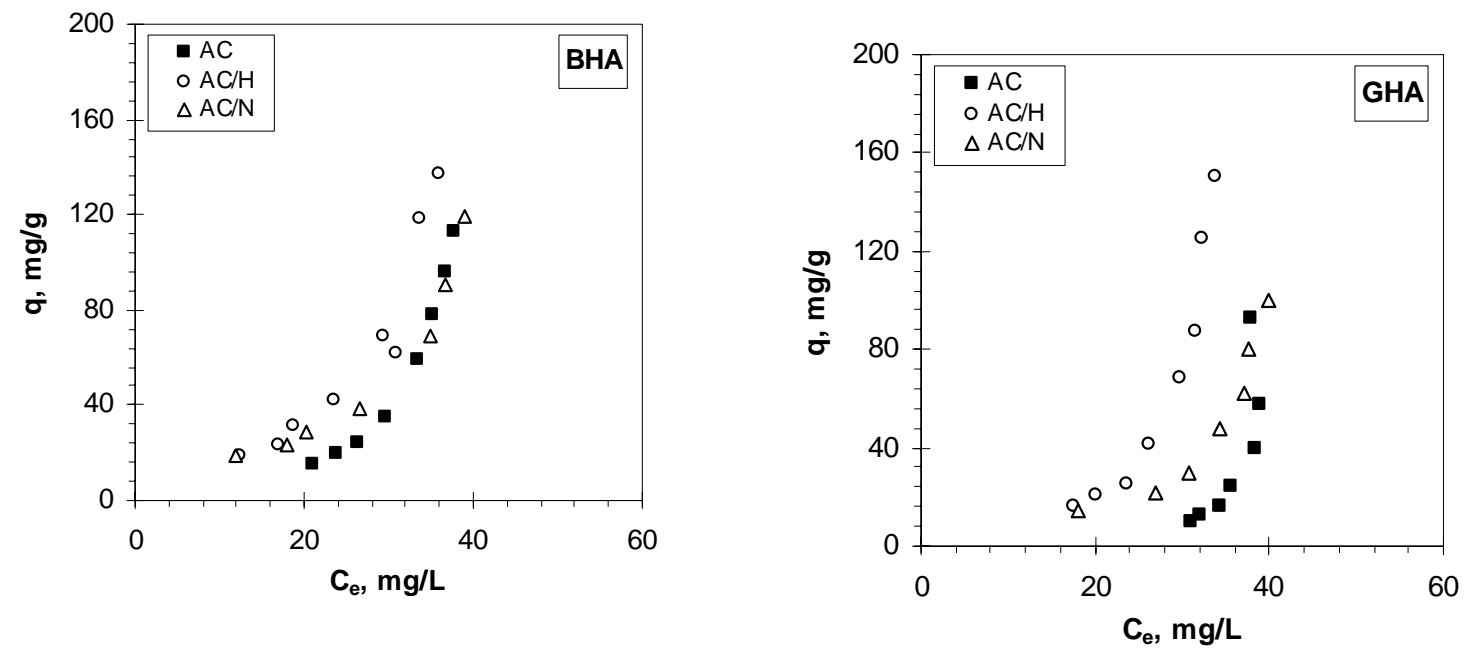

Figure 4. Isotherms of HAs adsorption on ACs.

Table 2. Parameters of Freundlich equation for BHA and GHA

\begin{tabular}{lcccccccc}
\hline \multirow{2}{*}{ Adsorbent } & \multicolumn{3}{c}{$\mathrm{BHA}$} & & \multicolumn{3}{c}{$\mathrm{GHA}$} \\
\cline { 2 - 4 } \cline { 7 - 9 } & $1 / \mathrm{n}$ & $\mathrm{K}_{\mathrm{f}}$ & $\mathrm{R}^{2}$ & & $1 / \mathrm{n}$ & $\mathrm{K}_{\mathrm{f}}$ & $\mathrm{R}^{2}$ \\
\hline $\mathrm{AC}$ & 3.72 & $0.14 \cdot 10^{-3}$ & 0.966 & & 9.77 & $1.97 \cdot 10^{-14}$ & 0.879 \\
$\mathrm{AC}-\mathrm{N}$ & 1.62 & $2.54 \cdot 10^{-1}$ & 0.912 & & 4.22 & $1.72 \cdot 10^{-5}$ & 0.966 \\
$\mathrm{AC}-\mathrm{H}$ & 2.02 & $8.64 \cdot 10^{-2}$ & 0.907 & & 5.08 & $2.53 \cdot 10^{-6}$ & 0.986 \\
\hline
\end{tabular}

The experimental equilibrium isotherms for adsorption of BHA and GHA on $\mathrm{AC}, \mathrm{AC} / \mathrm{N}$ and $\mathrm{AC} / \mathrm{H}$ are shown in Figure 4. Correlation coefficients of linear plots of $\log \mathrm{q}_{\mathrm{e}}$ versus $\log \mathrm{C}_{\mathrm{e}}$ range from 0.907 to 0.966 and from 0.879 to 0.986 for BHA and GHA, respectively. The concave alignments of the isotherms indicate a strong competition between the solute and the adsorbate molecules for active sites on the carbon surface. Presumably, water molecules form hydrophilic coating cluster, hindering therefore the adsorption of HA molecule. Once adsorbed HA molecule favors the adsorption of another one. The effect of such "induced" adsorption is stronger in case of more hydrophobic GHA, as can be deduced from more vertical course of the isotherm (Figure 4). In case of BHA adsorption, a smaller increase of sorption capacity $(\mathrm{q})$ with equilibrium concentration $\left(\mathrm{C}_{\mathrm{e}}\right)$ was observed. Water molecules can easier cover adsorbed BHA species lowering the effect of "induced" adsorption due to the higher content of carboxylic groups compared to GHA. A significant shift in the direction of 
the higher equilibrium concentrations was observed for GHA that indicates more unfavorable adsorption in comparison to BHA. This finding is consistent with the values of $K_{f}$ and $1 / n$ parameters calculated from, respectively, the intercept and the slope of the logarithmic plots of Freundlich equation (see Table 2). All 1/n values are higher than unity for both BHA and GHA, indicating unfavorable adsorption. The data presented in Table 2 show that $1 / \mathrm{n}$ values are 2,5-fold times higher for GHA than BHA confirming lower affinity of GHA molecules towards adsorbent surface. This suggests that preferential adsorption reported for various NOM portions could arise not only from the size of NOM molecules to be adsorbed but also from the solution composition and its behavior in adsorption system.

\subsection{Influence of ionic strength}
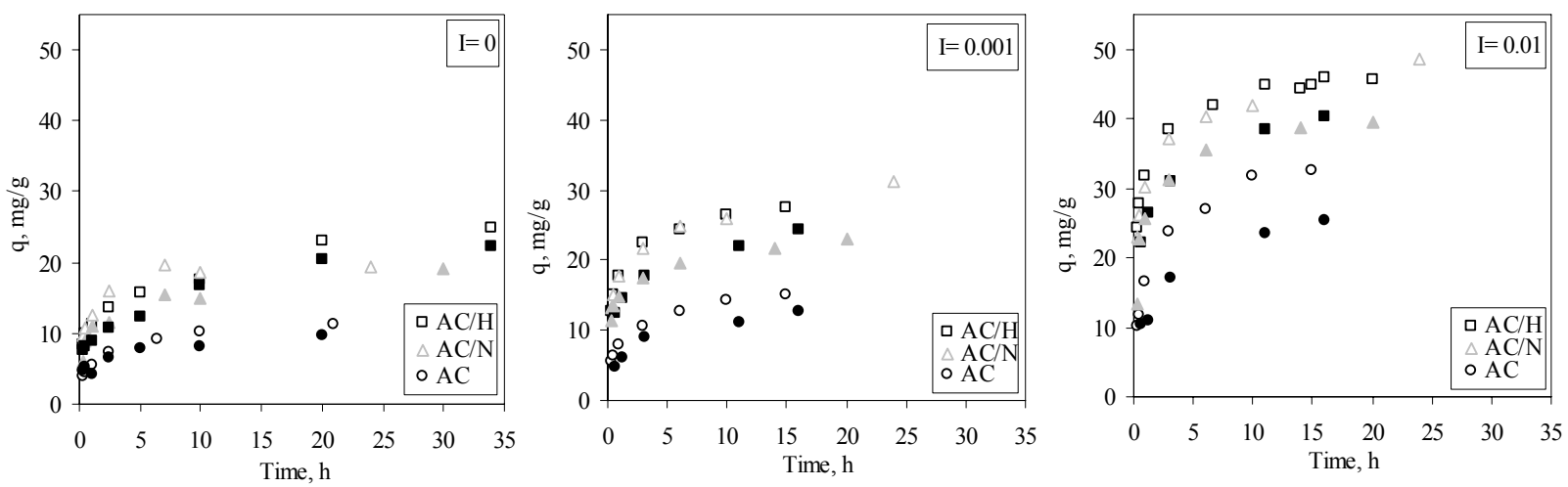

Figure 5. Adsorption of BHA (open symbols) and GHA (closed symbols) versus time for AC, $A C / N$ and $A C / H$ at various IS of the solution.

To determine the effect of ionic strength (IS) on HA adsorption, sodium chloride solutions at concentrations of 0.001 and 0.01 were used. The role of ionic strength in the adsorption process of HA has been widely investigated and reported in the literature [2],[4]. The uptake of BHA and GHA versus time at increasing IS on $\mathrm{AC}, \mathrm{AC} / \mathrm{N}$ and $\mathrm{AC} / \mathrm{H}$ is shown in Figure 5. An increase in the IS of the solution not only enhances the sorption capacity towards both BHA and GHA but also influences the kinetic of the process increasing significantly the adsorption rate. The presence of electrolyte in the adsorption system leads to decline of lateral repulsive forces between either HA molecules already adsorbed on the surface of activated carbon and HA molecules in the solution or molecules in the solution between themselves. This facilitates further adsorption and transport of the solute to the surface of the carbon.

It is evident that an increase in IS of the solution enhances the adsorption extent of both BHA and GHA, regardless of the chemical character of the adsorbent surface. Moreover, the removal degree of BHA and GHA on modified activated carbons is higher compared to nonmodified AC at any ionic strength tested. It should be noticed that sorption capacity remains lower towards GHA compared to BHA independently from the ionic strength of the solution. This can be explained by the difference in molecular size and/or aromacity of HA fractions studied. BHA, which is composed of lower molecular weight species and characterized by higher aromacity degree, will be preferentially removed by AC in the adsorption system where electrostatic interaction are screened by the presence of background electrolyte.

On the other hand, at high ionic strength, the difference in adsorption extent between $\mathrm{AC} / \mathrm{N}$ and $\mathrm{AC} / \mathrm{H}$ was insignificant. This suggests that IS applied is high enough to screen the charge on the BHA and GHA molecules as well as on the ACs surface. Thus, the dispersive 
interaction between hydrophobic portion of GHA or BHA and basal planes of AC remains the only adsorption driving force.

\section{CONCLUSIONS}

Adsorption of BHA and GHA on series of modified mesoporous activated carbons has been studied. No significant differences were observed in sorptive behavior of individual fractions in relate to different surface chemistry of adsorbent. High temperature hydrogen treated $(\mathrm{AC} / \mathrm{H})$ and ammonia treated $(\mathrm{AC} / \mathrm{N})$ activated carbons showed a much higher uptake of both BHA and GHA compared to starting AC. An enhanced BHA and GHA adsorption on $\mathrm{AC} / \mathrm{N}$ was due to the increase in aromacity degree (and hence, dispersive forces) of adsorbent, as shown by $\mathrm{C} / \mathrm{H}$ atomic ratio. The highest $\mathrm{BHA}$ and $\mathrm{GHA}$ uptake observed for $\mathrm{AC} / \mathrm{H}$ resulted from the occurrence of both dispersion forces and electrostatic interaction between the positively charged surface of $\mathrm{AC} / \mathrm{H}$ and the $\mathrm{HA}$ molecules. All ACs studied showed a slightly higher adsorption capacity towards BHA in comparison to GHA that is probably attributed to the lower both the molecular weight and the size of BHA. The shape of Freundlich isotherms indicated a strong competition for adsorption centers on AC surface between water and HA molecules, decreasing with increasing hydrophobicity of the AC surface. The values of Freundlich parameters obtained indicated unfavorable adsorption of both HA fractions on the series of modified activated carbons. However, a significant portion of BHA (61 \%) and GHA (51 \%) was removed applying AC/H.

Regardless of the chemical character of the adsorbent surface, an increase in IS of the solution enhances the adsorption extent of both BHA and GHA. Moreover, a comparable uptake of HA for $\mathrm{AC} / \mathrm{N}$ and $\mathrm{AC} / \mathrm{H}$ at ionic strengths of $0.001 \mathrm{M}$ and $0.01 \mathrm{M}$ was observed. This suggests that dispersive interaction are mainly responsible for the adsorption process due to the screening of the charge on the surface of the modified ACs and the HAs molecules, as well.

\section{ACKNOWLEDGEMENT}

The authors remain grateful to dr J.M. García-Mina, dr M. Fuentes and dr R. Baigorri from CIPAV-Roullier Group, Poligono Arazuri-Orcoyen, Navarra for providing the humic acid samples.

\section{REFERENCES}

[1] Watt B.E., Malcolm R.L., Hayes M.H.B., Clark N.W.E. Chipman J.K., Wat. Res. 1996, 30, 1502-1516.

[2] Newcombe G., Drikas M., Carbon, 1997, 35, 1239-1250.

[3] Karanfil T., Kilduff J.E., Schlautman M.A., Weber W.J., Environ. Sci. Technol. 1996, 30, 2187-2194.

[4] Duan J., Wilson F., Graham N., Tay J.H., Desalination 2002, 151, 53-66.

[5] Cheng W., Dastgheib S.A., Karanfil T., Wat.Res. 2005, 39, 2281-2290.

[6] Baigorri R., Zamarreño A.M., Fuentes M., González-Gaitano G., GarcíaMina J.M., Almendros G., González-Vila F.J., J. Agric. Food Chem. 2008, 56, 5480-5487.

[7] Baigorri R., Fuentes M., González-Gaitano G., García-Mina J.M., J. Phys. Chem. B 2007, 111, 10577-10582.

[8] Lorenc-Grabowska E., Gryglewicz G., Gryglewicz S., Microporous and Mesoporous Materials 2004, 76, 193-201. 
[9] Moreno-Castilla C., López-Ramón M.V., Carrasco-Marín F., Carbon , 2000, 38, 1995-2001.

[10] Jansen R.J.J., van Bekkum H., Carbon 1995, 33, 1021-1027.

[11] Newcombe G., Drikas M., Hayes R., Wat. Res. 1997, 31, 1065-1073.

[12] Radovic L.R., Silva I.F., Ume J.I., Menéndez J.A., Leon y Leon C.A., Scaroni A.W., Carbon 1997, 35, 1339-1348.

[13] Water quality control handbook, Roberts Alley E. (Ed.), McGrow-Hill Companies, New York, 2007, p. 9.68.

[14] Newcombe G., Wat. Sci. Tech. 1999, 40, 191-198. 